\title{
Mindfulness in mood and anxiety disorders: a review of the literature
}

\author{
Mindfulness nos transtornos do humor e ansiedade: uma revisão da literatura
}

Michele F. Rodrigues, Antonio E. Nardi, Michelle Levitan*

\begin{abstract}
Introduction: The objective of this study was to conduct a review of the literature covering the use of different mindfulnessbased therapy approaches in treatment of mood and anxiety disorders, including mindfulness skills and mindfulness linked to emotional regulation and fear of negative appraisal.

Methods: A review was conducted of literature identified by searching the scientific databases PubMed and PsycINFO with the following keywords: mindfulness, mood disorders, and anxiety disorders. The search covered the past 10 years. The search returned 532 articles, 24 were selected, their full texts were read, and 16 were included in this review.

Results: Six articles about mindfulness-based stress reduction, four about mindfulness-based cognitive therapy, and three about fear of negative appraisal and emotional regulation were reviewed. All of the articles covered mindfulness in relation to mood and anxiety disorders.

Conclusions: The literature in this field suggests that mindfulness is an effective strategy for the treatment of mood and anxiety disorders and is effective in therapy protocols with different structures including virtual modalities. Use of mindfulness in scientific models continues to expand.
\end{abstract}

Keywords: Mindfulness, mood disorders, anxiety disorders.

\section{Resumo}

Introdução: O objetivo deste estudo foi fazer uma revisão da literatura abrangendo o uso das diferentes abordagens da terapia baseada em mindfulness no tratamento dos transtornos de humor e ansiedade, incluindo suas habilidades e sua relação com a regulação emocional e com o medo da avaliação negativa.

Métodos: Uma revisão de literatura foi realizada através de busca pelas bases científicas PubMed e PsyciNFO, com as seguintes palavras-chave: mindfulness, transtornos do humor e transtornos de ansiedade. A pesquisa abrangeu os últimos 10 anos. A busca resultou em 532 artigos, sendo 24 selecionados e 16 incluídos nesta revisão.

Resultados: Foram revisados seis artigos sobre programa de redução de estresse baseado em mindfulness, quatro artigos sobre terapia cognitiva baseada em mindfulness, e três sobre medo da avaliação negativa e regulação emocional. Todos os artigos abordaram mindfulness com relação aos transtornos de humor e ansiedade

Conclusão: A literatura nessa área sugere que mindfulness é uma estratégia eficaz no tratamento dos transtornos de humor e ansiedade e é eficaz no protocolo de terapia em diferentes formatos, incluindo virtual. $\mathrm{O}$ uso de mindfulness continua a se expandir nos modelos científicos.

Descritores: Mindfulness, transtornos do humor e transtornos ansiosos.

\footnotetext{
* Laboratório de Pânico e Respiração (LABPR), Instituto de Psiquiatria, Universidade Federal do Rio de Janeiro (UFRJ), Rio de Janeiro, RJ, Brazil. Submitted Jul 14 2016, accepted for publication Nov 252016.

Suggested citation: Rodrigues MF, Nardi AE, Levitan M. Mindfulness in mood and anxiety disorders: a review of the literature. Trends Psychiatry Psychother. 2017;39(3):207-215. Epub 31 July 2017. http://dx.doi.org/10.1590/2237-6089-2016-0051
} 


\section{Introduction}

Mindfulness can be described as a process of sustained attention and awareness toward present-moment sensations and experiences with a nonjudgmental stance. Mindfulness is considered a means of achieving pleasure, wisdom, and connectedness, ${ }^{1,2}$ and if practiced properly it improves both mental and physical health. Some treatments for anxiety and mood disorders incorporate aspects of the practice of mindfulness and show beneficial effects on treatment outcomes. While studies have observed the efficacy of mindfulness, the mechanisms behind mindfulness and its association with symptoms of depression and anxiety are still not well known. ${ }^{3}$

Mindfulness has been associated with some psychotherapeutic approaches comprising mindfulnessbased stress reduction (MBSR) and mindfulness-based cognitive therapy (MBCT) ${ }^{4}$ The MBSR approach includes daily mindfulness activities related to awareness of mind and body, using techniques focused on the present moment and nonjudgment. ${ }^{5}$ The MBCT approach is based on integration of cognitive behavioral therapy (CBT) with MBSR and is designed to reduce relapse and recurrence of major depression. ${ }^{6}$ Moreover, internetbased mindfulness treatments delivered remotely have also been studied and the results show positive outcomes for treatment of anxiety disorders. ${ }^{7}$

The unique prognostic capability of mindfulness skills, such as, for example, observing, describing, and acting with awareness, nonjudgmentally, and nonreactively, has been examined. Emotional regulation is a practice through which people temper their emotions in response to environmental obstacles in order to accomplish their aims. A link has been found between difficulties with emotional regulation and psychopathology, primarily among people with mood and anxiety disorders. ${ }^{3}$ Fear of negative appraisal decreased with successive treatments and was negatively associated with mindfulness throughout treatment and follow-up. ${ }^{8}$

One study evaluated mindfulness group therapy as an alternative to standard treatment (mostly individual CBT) for patients with clinical diagnoses of anxiety and stress and depressive and adjustment disorders. The study sample comprised 215 eligible patients. One hundred and ten participants received the group psychotherapeutic intervention and were compared with a control group of 105 participants given standard treatment. Variability between the mindfulness and control groups was non-significant and the mindfulness group protocols were found to be equally effective to regular treatment. The group treatment was based on two mindfulness-based therapies, MBSR and MBCT. ${ }^{9}$
A trial study evaluated the efficacy of an internetbased mindfulness treatment program for anxiety. The study randomly assigned 91 subjects diagnosed with social anxiety disorder, generalized anxiety disorder, panic disorder, or anxiety disorder to a mindfulness treatment group (MTG) or a discussion forum control group (CG). The main difference from traditional faceto-face delivery was the lack of contact with a clinician and with other patients in the internet setting. The study concluded that mindfulness exercises carried out face-to-face or remotely via the internet both appear to result in similar changes in symptoms. The remote delivery mode did not appear to decrease the effect of the mindfulness intervention. ${ }^{7}$

One study examined the use of specific mindfulness skills, in contrast to other research focused on the global construct of mindfulness or the effectiveness of mindfulness-based interventions. An understanding of these skills may reveal the mechanisms by which mindfulness works and improves outcomes in mindfulness-based interventions. The study examined the effects of specific mindfulness skills (observing, describing, acting with awareness, nonjudging of inner experience, and nonreacting to inner experience) on symptoms of panic psychopathology, also known as panic symptoms, anxiety sensitivity, and body vigilance among adults with asthma. The study's findings suggested that focusing on the skill of acting with awareness may be a new approach to eliminating panic symptomatology among individuals with asthma. Through this skill, participants paid attention to the current moment when engaging in activities, as opposed to acting unconsciously or on "auto-pilot," and were therefore less likely to fear arousal-related sensations and experience panic-related symptoms. ${ }^{10}$

Mindfulness has been the subject of numerous selfhelp books and courses, resulting in outcomes such as higher self-esteem and lower neuroticism. It has also been consistently linked to lower rates of depression and anxiety and greater well-being. ${ }^{11}$ The aim of this study was to conduct a literature review to identify the different ways in which mindfulness benefits patients with mood and anxiety disorders.

\section{Methods}

A literature review was carried out of publications indexed on two databases (PubMed and PsycINFO), using the search terms mindfulness, mood disorders, and anxiety disorders. The review was performed in July 2016 and all of the searches were limited to articles published between January 2006 and July 2016. 
A total of 532 references were found listed on PsycINFO and PubMed. From this total, 26 were not in English, and 104 were duplicate references. The remaining 402 references underwent title (354) and abstract analyses (24), resulting in exclusion of 378 references. After these analyses, 24 references remained, their full texts were read, and 16 of them were selected for this review. Figure 1 illustrates the steps of this search strategy.

This literature review showed that there is a link between mindfulness-based interventions and anxiety and mood disorders. A total of 10 mindfulness-based interventions were found to include MBCT and/or MBSR.
All of the interventions involved 8-week sessions, and the duration of these sessions varied from two to three hours.

\section{Results}

\section{Mindfulness-based therapies}

Mindfulness-based stress reduction (MBSR)

MBSR is a theory that drives treatments linking the body-mind connection, sitting meditation, and relaxation, both in an individual and group setting, and focused on the practice of mindfulness. In 2015, Eyles et al. used a convergent design combining qualitative

Keywords: mindfulness, anxiety disorder, mood disorder.
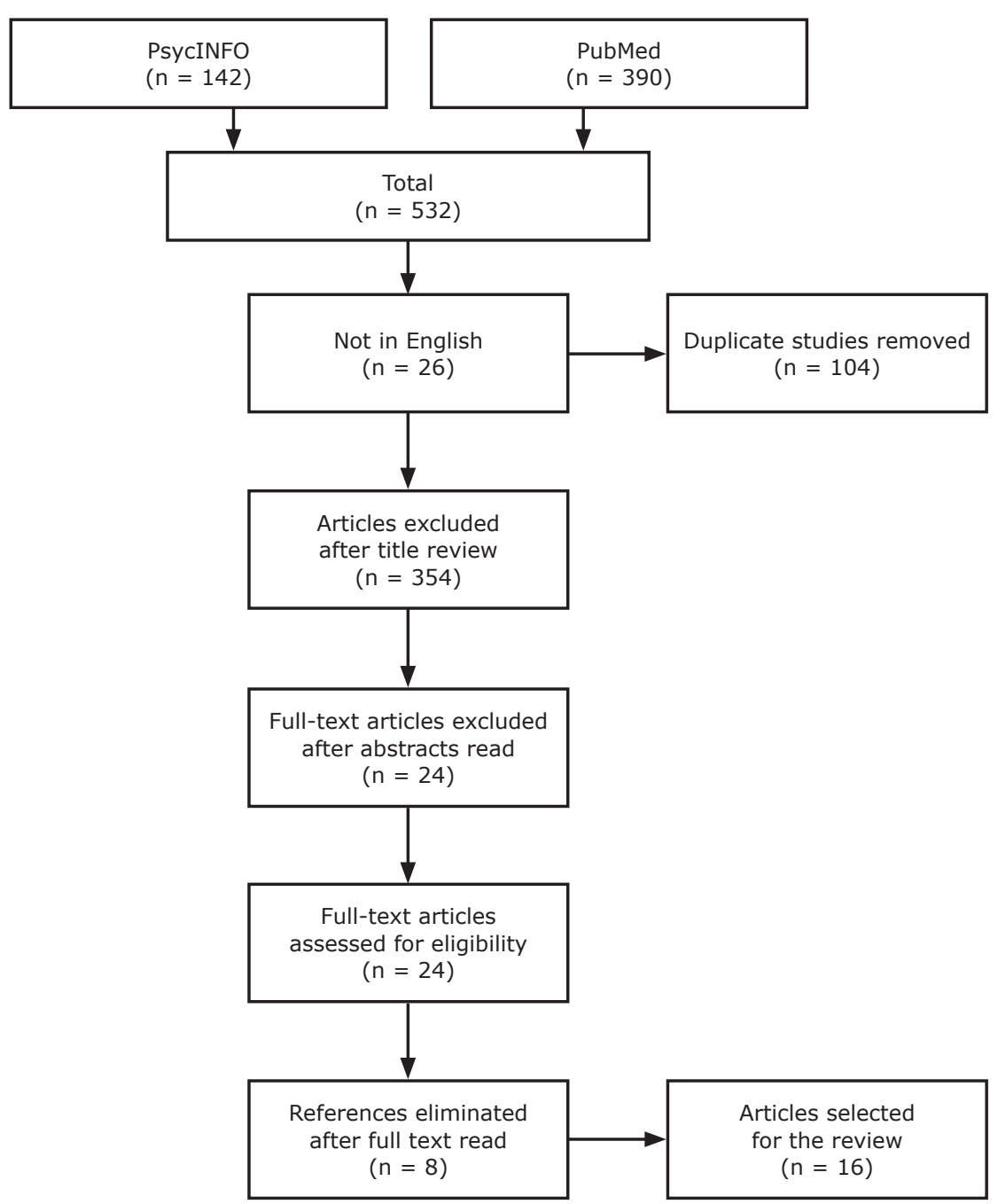

Figure 1 - Results of the literature review 
and quantitative methods to examine the acceptability and achievability of providing MBSR to women with metastatic breast cancer (MBC) and of implementing MBSR in a National Health Service setting. The study approached 100 women, and 19 of them took part in the therapeutic intervention, enrolling on one of 3 MBSR courses. The study implemented MBSR-based treatment in women with MBC who were experiencing enhanced anxiety and effects on their quality of life (QoL). The MBSR-based treatment was accepted by MBC patients, who reported it was beneficial for their anxiety and QoL. ${ }^{12}$ Another study, conducted by Smith et al used an abbreviated MBSR course and examined its effects on anxiety, stress, and depression. ${ }^{5}$

In a study by Hoge et al., body scanning and breath awareness were used during classes to gain an understanding of internal present-moment experiences. In the majority of studies, the MBSR program consisted of 8 weekly group classes with a single weekend "retreat" day and daily home practice guided by audio recordings. ${ }^{13}$ One exception was a study by Lenze et al., in which a sample of 89 patients was selected, 34 of whom were recruited to participate in the study. Sixteen participants were assigned to an 8-session MBSR program, and 18 participants were assigned to a 12-session MBSR program. The study showed that MBSR was effective in anxious older adults; the patients experienced positive developments such as decreased worry severity and improved memory. The data did not show a significant difference in cognitive or clinical performance due to MBSR techniques in the 12-week MBSR program compared to the 8 -week MBSR program. ${ }^{14}$

The Hoge et al. study observed that mindfulness meditation training diminished anxiety symptoms in patients with general anxiety disorder (GAD). The study also showed that mindfulness meditation led to enhanced coping during a laboratory stress paradigm, due to resilience during stressful psychological questions. An active control group (SME - Stress Management Education) was used to examine the effect of MBSR on GAD. The analysis comprised 89 participants; forty-eight subjects completed MBSR, and 41 subjects completed at least one session of SME. The MBSR and SME interventions revealed substantial decreases in Hamilton Anxiety Scale HAM-A scores at the endpoint; however, these differences were not observed throughout the entire course of treatment. ${ }^{13}$

One study noted that the effects of MBSR on veterans included improved symptoms of anxiety and depression and a reduction in suicidal ideation. ${ }^{15}$ Another study of veterans conducted a randomized clinical trial comparing adapted MBSR with CBT in treatment groups for anxiety disorders, and both groups revealed similar outcomes across most results, with several exceptions. The CBT group focused on treating anxiety disorder symptoms, and the MBSR group more broadly emphasized redirecting participants' attention to the current moment and shifting their primary relationship with thoughts, feelings, and the present internal experience, which led to larger symptom effects (external anxiety). The CBT intervention resulted in more improvement in anxious arousal effects at follow up, while the adapted MBSR intervention resulted in superior improvements in co-occurring mood disorders and reduced worry, but also showed greater severity of these measures at the pretreatment stage, confounding the interpretation of these results. The severity of the primary anxiety disorders was rated by clinicians who were blind to the treatment groups, and a comparison of clinician diagnoses indicated large effect sizes across both treatment groups. In contrast, the effect sizes on the self-report results showed more modest advances. The CBT and adapted MBSR interventions were mutually effective at reducing the primary diagnoses and fairly effective at reducing self-reported anxiety symptoms within the trial. The overall findings suggested that the CBT and adapted MBSR interventions resulted in similar rates of therapeutic change. ${ }^{16}$

\section{Mindfulness-based cognitive therapy (MBCT)}

The MBCT approach comprises cognitive therapy techniques that address mood symptoms and negative thoughts, as well as rumination, avoidance, suppression, and struggles with dysfunctional cognition and emotions that can sustain distress. MBCT, developed by Zindel Segal, Mark Williams, and John Teasdale, emphasizes acceptance rather than a change of strategies, and it offers no training on changing the content of thoughts, but rather encourages viewing thoughts as thoughts instead of reflections of reality. Wong et al. proposed a protocol for a randomized controlled trial designed to compare an MBCT program, a psycho-education group with CBT principles, and usual care with MBCT at the study's conclusion, for ethical reasons (the MBCT and PEG groups would consist of 8 -week sessions lasting 2 hours each). 6,17

One study observed the affective component of the cognitive-affective associative network and assessed the effects of MBCT on emotional reactivity. Fiftytwo participants with clinical diagnoses of partially remitted depression were randomized into an 8-week MBCT course or a waitlist control condition. According to the study's findings, mindfulness meditation training was linked to decreased emotional reactivity despite a negative affect. In fact, negative affect and physiological arousal were found to be the stressors 
causing the development of emotional reactivity. This study supported the empirical basis for the relevance of mindfulness-based approaches in depressed patients. ${ }^{18}$

In another study, 80 subjects with panic disorders were selected to participate. Sixty-five subjects enrolled on an MBCT program, and 48 of the subjects completed the program. The program was carried out in 13 separate groups, with 12 participants in each group. The treatment effects that were evaluated included completion of the $\mathrm{MBCT}$, treatment response, and remission after completing MBCT. According to the study, the presence of comorbid personality disorders predicted the non-completion of MBCT for panic disorders. Likewise, treatment response and remission after $\mathrm{MBCT}$ could be predicted by enhanced anxiety sensitivity. ${ }^{19}$

One randomized controlled trial suggested that MBCT could be an effective additional therapy for patients with treatment-resistant depression having active depressive episodes. The study found that MBCT was more effective at reducing depression and rates of decline and debility when it was enhanced by regular medication than an active comparative disorder, thus highlighting the features of MBCT that might be most pronounced. The outcomes of this study have substantial implications for the treatment of depression with targeted, population-based, non-pharmacological intervention approaches. ${ }^{20}$

\section{Other associations}

\section{Emotional regulation and mindfulness}

One study used multiple simple mediation analyses to propose that mindfulness influences depression and anxiety symptoms through emotional regulatory mechanisms (rumination, reappraisal, worry, and non-acceptance) by considering emotional regulation a path through which mindfulness stimulates mental health. Emotional regulation is a practice by which individuals temper their emotions in response to environmental difficulties to achieve certain aims. The association between emotional regulation difficulties and psychopathology has primarily been found in mood and anxiety disorders. Rumination may be a contributor to anxiety, particularly due to repetitive thoughts about future negative events. For depression, rumination may involve repetitive thoughts about present and past negative consequences. However, reappraisal could work specifically with depressive and anxiety symptoms. ${ }^{3}$

Two additional studies found substantial connections between difficulties in emotional regulation, features of mindfulness (present moment awareness and acceptance/self-compassion), and GAD symptom severity and diagnoses. Study one included a sample of 395 individuals. Individuals with a principal diagnosis of GAD and non-anxious controls were subjected to a series of self-report procedures. Study two had sixteen participants and examined reduced levels of mindfulness (awareness and acceptance/nonjudgment) and complications in emotional regulation, concluding that both reflected GAD symptoms. The study also found that both involved awareness (monitoring) and acceptance of emotional responses. ${ }^{21}$

\section{Fear of negative appraisal and mindfulness}

One randomized controlled trial studied the link between self-reported mindfulness and fear of negative appraisal in nonmindfulness-based CBT for social anxiety disorder (SAD). The study was completed by 65 participants who were diagnosed with SAD. As part of the randomized controlled trial, the participants were assigned to three groups: virtual reality exposure (VRE) therapy (32 participants), exposure group therapy (EGT) (33 participants), and a waitlist control group. participants $(\mathrm{N}=65)$ diagnosed with SAD The participants received 8 weeks of the 2 standardized treatments either immediately after the treatment or following an 8 -week waiting period. ${ }^{8}$

The study findings suggested that individuals with symptoms of SAD and higher levels of mindfulness did not show better treatment responses than those with lower levels of mindfulness. One conceivable reason for this finding was that this clinical sample did not have adequate levels of mindfulness to make treatment improvements. However, mindfulness scores in the current trial were higher than those of other clinical samples and were more similar to the nonclinical sample. The lack of a significant outcome could be due to the fact that mindfulness did not increase due to the treatment. Other results showed that fear of negative appraisal decreased after the treatment and was negatively associated with mindfulness throughout the treatment and follow-up. The study indicated the interesting possibility that targeting mindfulness may improve CBT treatments for SAD. However, standard CBT alone did not affect mindfulness levels in SAD. ${ }^{8}$

Table 1 provides a summary of the studies and their participants' sociodemographic and clinical information. Table 2 provides more detailed descriptions of the studies, specifically, the characteristics of the interventions and their main findings.

\section{Discussion}

In this literature review, we examined the benefits of mindfulness and some other psychotherapeutic approaches for patients with mood and anxiety disorders. ${ }^{4}$ 
Table 1 - Details of studies reviewed: interventions and participants'sociodemographic and clinical data

\begin{tabular}{|c|c|c|c|c|c|}
\hline Study authors & Intervention & Sample size & Psychopathology & $\begin{array}{c}\text { Mean Age } \pm \text { SD } \\
\text { n (\%) }\end{array}$ & $\begin{array}{l}\text { Sex, male } \\
(\%)\end{array}$ \\
\hline Desrosiers et al. ${ }^{3}$ & NI & 187 & $M D, A D$ & $38(14.2)$ & 35.4 \\
\hline Smith B et al. ${ }^{5}$ & MBSR & 23 & $S, M D, A D$ & $54.9(12.0)$ & 4.3 \\
\hline Wong et al. ${ }^{6}$ & MBCT & 18 & GAD & NR & NR \\
\hline Boettcher et al. ${ }^{7}$ & $\begin{array}{l}\text { MTG } \\
\text { CG }\end{array}$ & 91 & SAD, GAD, PD, ADNOS & $\begin{array}{l}\text { MTG }=37(8.9) \\
\mathrm{CG}=40(11.5)\end{array}$ & $\begin{array}{c}M T G=24.4 \\
C G=28.6\end{array}$ \\
\hline Burton et al. ${ }^{8}$ & CBT & 65 & SAD & $40(12.0)$ & 39 \\
\hline Sundquist et al. ${ }^{9}$ & $\begin{array}{c}\text { MBSR } \\
\text { MBCT } \\
\text { CBT }\end{array}$ & 215 & S, MD, AD, AdjD & 42 & NR \\
\hline Kraemer et al. ${ }^{10}$ & NI & 56 & PD & $19.5(2.7)$ & 30.4 \\
\hline Eyles et al. ${ }^{12}$ & MBSR & 19 & $M D, A D$ & $37-65$ years & 0 \\
\hline Hoge et al. ${ }^{13}$ & $\begin{array}{l}\text { MBSR } \\
\text { SME }\end{array}$ & 89 & GAD & $\begin{array}{l}\text { MBSR }=41(14.0) \\
S M E=37(12.0)\end{array}$ & $\begin{array}{l}\mathrm{MBSR}=52 \\
\mathrm{SME}=46\end{array}$ \\
\hline Lenze et al. ${ }^{14}$ & MBSR & 34 & $\begin{array}{l}\text { GAD, ADNOS, MDE, PD, OCD, } \\
\text { DsyD, DD-NOS, PH, PHS }\end{array}$ & $\begin{array}{c}8 \text { weeks }=70.9(4.5) \\
12 \text { weeks }=70.7(4.9)\end{array}$ & $\begin{array}{c}8 \text { weeks }=31 \\
12 \text { weeks }=22\end{array}$ \\
\hline Serpa et al. ${ }^{16}$ & MBSR & 79 & $M D, A D$ & $60(7)$ & 89 \\
\hline Arch et al. ${ }^{17}$ & $\begin{array}{l}\text { MBSR } \\
\text { CBT }\end{array}$ & 105 & $\mathrm{PD} / \mathrm{A}, \mathrm{GAD}, \mathrm{SAD}, \mathrm{SP}, \mathrm{OCD}, \mathrm{PTSD}$ & $45.91(13.68)$ & 83 \\
\hline Britton et al. ${ }^{18}$ & MBCT & 52 & PRD & $47.03(1.9)$ & 15.51 \\
\hline Kim et al. ${ }^{19}$ & MBCT & 65 & PD & $39.94(9.13)$ & 47.7 \\
\hline Eisendrath et al. ${ }^{20}$ & $\begin{array}{l}\text { MBCT } \\
\text { HEP }\end{array}$ & NI & MDD & NI & NI \\
\hline Roemer et al. ${ }^{21}$ & NI & 411 & GAD & 32 & 33.5 \\
\hline
\end{tabular}

$\mathrm{AD}$ = anxiety disorder; AdjD = adjustment disorders; ADNOS = anxiety disorder not otherwise specified; CBT = cognitive behavioral treatment; CG = control group; DD-NOS = depressive disorder not otherwise specified; DsyD = dysthymic disorder; GAD = general anxiety disorder; HEP = Health Enhancement Program; MBCT = mindfulness based cognitive therapy; MBSR = mindfulness-based stress reduction; $M D=$ mood disorder; $M D E=$ major depressive episode; MTG = mindfulness treatment group; $\mathrm{NI}=$ no intervention; $\mathrm{NR}=$ not reported; $\mathrm{OCD}=$ obsessive-compulsive disorder; $\mathrm{PD} / \mathrm{A}=$ panic disorder with or without agoraphobia; $\mathrm{PH}=$ phobia; $\mathrm{PHS}=$ social phobia; $\mathrm{PRD}=$ partially-remitted depression; $\mathrm{PTSD}=$ posttraumatic stress disorder; $\mathrm{S}=$ stress; $\mathrm{SAD}=$ social anxiety disorder; $\mathrm{SD}=$ standard deviation; $\mathrm{SME}=$ stress management education; $\mathrm{SP}=$ specific phobia.

Table 2 - Descriptions of the studies reviewed: the characteristics of the interventions and their main findings

\begin{tabular}{|c|c|c|c|c|c|c|c|}
\hline $\begin{array}{l}\text { Study } \\
\text { authors }\end{array}$ & $\begin{array}{l}\text { Dose } \\
\text { (session } \\
\text { length) }\end{array}$ & $\begin{array}{l}\text { Frequency } \\
\text { (sessions } \\
\text { per week) }\end{array}$ & $\begin{array}{l}\text { Length of } \\
\text { intervention }\end{array}$ & Modality & Follow up & Outcomes & Main findings \\
\hline $\begin{array}{l}\text { Desrosiers } \\
\text { et } \text { al. }^{3}\end{array}$ & NI & NI & NI & NI & NI & $\begin{array}{l}\text { MASQ-AD, } \\
\text { ERQ, MASQ- } \\
\text { AA, RRS, } \\
\text { FFMQ, PSWQ, } \\
\text { DERS }\end{array}$ & $\begin{array}{l}\text { Some treatments for anxiety and } \\
\text { mood disorders incorporate aspects of } \\
\text { the practice of mindfulness and show } \\
\text { beneficial effects on treatment outcomes. }\end{array}$ \\
\hline Smith et al. ${ }^{5}$ & $\begin{array}{l}120 \min \\
\text { to } 180 \\
\text { min }\end{array}$ & $1 x /$ week & 8 weeks & $\begin{array}{l}\text { Group-based } \\
\text { session plus } \\
\text { home based } \\
\text { exercise and } \\
\text { 6-hour retreat }\end{array}$ & $\begin{array}{l}\text { Immediately } \\
\text { after the } \\
\text { intervention }\end{array}$ & $\begin{array}{l}\text { GAD-7 } \\
\text { PSS-4 } \\
\text { SF-36 }\end{array}$ & $\begin{array}{l}\text { The MBSR approach includes daily } \\
\text { mindfulness activities related to } \\
\text { awareness of mind and body, using } \\
\text { techniques focused on the present } \\
\text { moment and nonjudgment. }\end{array}$ \\
\hline Wong et al. ${ }^{6}$ & $120 \mathrm{~min}$ & $1 x /$ week & 8 weeks & $\begin{array}{l}\text { Group-based } \\
\text { session plus } \\
\text { home based } \\
\text { exercise }\end{array}$ & $\begin{array}{l}3 \text { months } \\
6 \text { months } \\
9 \text { months }\end{array}$ & $\begin{array}{l}\text { PSWQ, BAI } \\
\text { CES-D } \\
\text { SF-12 }\end{array}$ & $\begin{array}{l}\text { The MBCT approach is based on an } \\
\text { integration of CBT and MBSR and is } \\
\text { designed to reduce the rates of relapse } \\
\text { and recurrence of major depression. }\end{array}$ \\
\hline $\begin{array}{l}\text { Boettcher et } \\
\text { al. }{ }^{7}\end{array}$ & $120 \mathrm{~min}$ & $1 \mathrm{x} /$ week & 8 weeks & $\begin{array}{l}\text { Internet based } \\
\text { treatment plus } \\
\text { home based } \\
\text { exercise }\end{array}$ & 6 months & $\begin{array}{l}\text { BAI } \\
\text { BDI } \\
\text { ISI } \\
\text { QOLI }\end{array}$ & $\begin{array}{l}\text { Internet-based mindfulness treatments } \\
\text { that are delivered remotely were studied, } \\
\text { showing positive outcomes of treatment } \\
\text { of anxiety disorders. }\end{array}$ \\
\hline Burton et al. ${ }^{8}$ & NR & $1 x /$ week & 8 weeks & $\begin{array}{l}\text { Virtual reality } \\
\text { exposure or } \\
\text { exposure } \\
\text { group therapy }\end{array}$ & 3 months & $\begin{array}{l}\text { BFNE } \\
\text { MAAS }\end{array}$ & $\begin{array}{l}\text { Fear of negative appraisal decreased } \\
\text { with successive treatments and was } \\
\text { negatively associated with mindfulness } \\
\text { throughout treatment and follow-up. }\end{array}$ \\
\hline
\end{tabular}




\begin{tabular}{|c|c|c|c|c|c|c|c|}
\hline $\begin{array}{l}\text { Study } \\
\text { authors }\end{array}$ & $\begin{array}{l}\text { Dose } \\
\text { (session } \\
\text { length) }\end{array}$ & $\begin{array}{l}\text { Frequency } \\
\text { (sessions } \\
\text { per week) }\end{array}$ & $\begin{array}{l}\text { Length of } \\
\text { intervention }\end{array}$ & Modality & Follow up & Outcomes & Main findings \\
\hline $\begin{array}{l}\text { Sundquist } \\
\text { et al. }{ }^{9}\end{array}$ & $120 \mathrm{~min}$ & $1 x /$ week & 8 weeks & $\begin{array}{l}\text { Group-based } \\
\text { session plus } \\
\text { home based } \\
\text { exercise }\end{array}$ & $\begin{array}{l}\text { Immediately } \\
\text { after the } \\
\text { intervention }\end{array}$ & $\begin{array}{l}\text { HADS } \\
\text { PHQ-9 } \\
\text { MADRS-S }\end{array}$ & $\begin{array}{l}\text { The variations between the mindfulness } \\
\text { and control groups were irrelevant, } \\
\text { therefore their protocols was non-inferior } \\
\text { to treatment as usual for patients. }\end{array}$ \\
\hline $\begin{array}{l}\text { Kraemer et } \\
\text { al. }^{10}\end{array}$ & NI & NI & NI & NI & NI & $\begin{array}{l}\text { PANAS } \\
\text { FFMQ } \\
\text { ASI-3 } \\
\text { IDAS }\end{array}$ & $\begin{array}{l}\text { The study's findings suggested that } \\
\text { targeting use of the skill of acting with } \\
\text { awareness may be a new approach } \\
\text { to eliminating panic symptomatology } \\
\text { among individuals with asthma. }\end{array}$ \\
\hline Eyles et al. ${ }^{12}$ & $120 \mathrm{~min}$ & $1 \mathrm{x} /$ week & 8 weeks & $\begin{array}{l}\text { Group-based } \\
\text { session plus } \\
\text { retreat day } \\
\text { and home } \\
\text { based exercise }\end{array}$ & $\begin{array}{l}4 \text { months } \\
6 \text { months }\end{array}$ & $\begin{array}{l}\text { HADS } \\
\text { BFI } \\
\text { TMS }\end{array}$ & $\begin{array}{l}\text { The study implemented an MBSR-based } \\
\text { treatment in women with MBC who were } \\
\text { experiencing enhanced anxiety and } \\
\text { effects on their QoL. The MBSR-based } \\
\text { treatment was accepted by MBC patients } \\
\text { who reported its benefits on their anxiety } \\
\text { and QoL. }\end{array}$ \\
\hline Hoge et al. ${ }^{13}$ & $120 \mathrm{~min}$ & $1 x /$ week & 8 weeks & $\begin{array}{l}\text { Group-based } \\
\text { session plus } 4 \\
\text { hour retreat } \\
\text { and home } \\
\text { based exercise }\end{array}$ & $\begin{array}{l}\text { Immediately } \\
\text { after the } \\
\text { intervention }\end{array}$ & $\begin{array}{l}\text { HAM-A } \\
\text { BAI }\end{array}$ & $\begin{array}{l}\text { In the majority of studies, the MBSR } \\
\text { program consisted of } 8 \text { weekly group } \\
\text { classes with a single weekend "retreat" } \\
\text { day and daily home practice guided by } \\
\text { audio recordings. }\end{array}$ \\
\hline Lenze et al. ${ }^{14}$ & $150 \mathrm{~min}$ & $1 x /$ week & $\begin{array}{l}8 \text { weeks } \\
12 \text { weeks }\end{array}$ & $\begin{array}{l}\text { Group-based } \\
\text { session plus } \\
\text { one day-long } \\
\text { retreat or } 2.5 \\
\text { hour retreat }\end{array}$ & $\begin{array}{l}3 \text { months } \\
6 \text { moths }\end{array}$ & $\begin{array}{l}\text { MAAS } \\
\text { CAMS-R }\end{array}$ & $\begin{array}{l}\text { The study showed that MBSR was } \\
\text { effective in anxious older adults; } \\
\text { the patients experienced positive } \\
\text { developments such as decreased worry } \\
\text { severity and improved memory. }\end{array}$ \\
\hline Serpa et al. ${ }^{16}$ & $120 \mathrm{~min}$ & $1 \mathrm{x} /$ week & 9 weeks & $\begin{array}{l}\text { Group-based } \\
\text { session plus } \\
\text { home based } \\
\text { exercise }\end{array}$ & $\begin{array}{l}\text { Immediately } \\
\text { after the } \\
\text { intervention }\end{array}$ & $\begin{array}{l}\text { SF-12 } \\
\text { FFMQ } \\
\text { PHQ-9 }\end{array}$ & $\begin{array}{l}\text { The data did not show a significant } \\
\text { difference in cognitive or clinical } \\
\text { performance due to MBSR techniques in } \\
\text { the } 12 \text {-week MBSR program compared to } \\
\text { the } 8 \text {-week MBSR program. }\end{array}$ \\
\hline Arch et al. ${ }^{17}$ & $90 \mathrm{~min}$ & $1 x /$ week & 10 weeks & $\begin{array}{l}\text { Group-based } \\
\text { session plus a } \\
\text { single } 3 \text { hour } \\
\text { retreat and } \\
\text { home based } \\
\text { exercise }\end{array}$ & 3 months & $\begin{array}{l}\text { BDI } \\
\text { MASQ-AA } \\
\text { PSWQ }\end{array}$ & $\begin{array}{l}\text { They noted that the effects of MBSR on } \\
\text { veterans included improved symptoms of } \\
\text { anxiety and depression and a reduction } \\
\text { in suicidal ideation. }\end{array}$ \\
\hline $\begin{array}{l}\text { Britton et } \\
\text { al. }{ }^{18}\end{array}$ & NR & $1 x /$ week & 8 weeks & $\begin{array}{l}\text { Group-based } \\
\text { session plus } \\
\text { home based } \\
\text { exercise }\end{array}$ & & $\begin{array}{l}\text { TSST, BDI, } \\
\text { HRST } \\
\text { STAI-Y1 }\end{array}$ & $\begin{array}{l}\text { The CBT and adapted MBSR interventions } \\
\text { were mutually effective at reducing the } \\
\text { primary diagnoses and fairly effective at } \\
\text { reducing self-reported anxiety symptoms } \\
\text { within the trial. }\end{array}$ \\
\hline Kim et al. ${ }^{19}$ & $90 \mathrm{~min}$ & $1 x /$ week & 8 weeks & $\begin{array}{l}\text { Group-based } \\
\text { session plus } \\
\text { home based } \\
\text { exercise }\end{array}$ & 1 year & $\begin{array}{l}\text { PDSS, } \\
\text { HAM-D } \\
\text { ASI-R, } \\
\text { HAM-A }\end{array}$ & $\begin{array}{l}\text { This study supported the empirical basis } \\
\text { for the relevance of mindfulness-based } \\
\text { approaches in depressed patients. }\end{array}$ \\
\hline $\begin{array}{l}\text { Eisendrath et } \\
\text { al. }{ }^{20}\end{array}$ & $135 \mathrm{~min}$ & $1 x /$ week & 8 weeks & $\begin{array}{l}\text { Group-based } \\
\text { session plus } \\
\text { home based } \\
\text { exercise }\end{array}$ & $\begin{array}{l}6 \text { months } \\
9 \text { months } \\
13 \text { months }\end{array}$ & $\begin{array}{l}\text { HAM-D, } \\
\text { SF-12, } \\
\text { QIDS, WSAS } \\
\text { Q-LES-SQ } \\
\text { AAQ, RRS, } \\
\text { SCS }\end{array}$ & $\begin{array}{l}\text { The presence of comorbid personality } \\
\text { disorders predicted non-completion of } \\
\text { MBCT for panic disorders. Likewise, } \\
\text { treatment response and remission after } \\
\text { MBCT could be predicted by enhanced } \\
\text { anxiety sensitivity. }\end{array}$ \\
\hline $\begin{array}{l}\text { Roemer et } \\
\text { al. }{ }^{21}\end{array}$ & NI & NI & NI & NI & NI & $\begin{array}{l}\text { DERS } \\
\text { PSWQ } \\
\text { MAAS } \\
\text { SCS } \\
\text { DASS-21 }\end{array}$ & $\begin{array}{l}\text { Lack of emotion regulation and aspects } \\
\text { of mindfulness was noticed in GAD } \\
\text { patients in both studies. }\end{array}$ \\
\hline
\end{tabular}

$\mathrm{AAQ}=$ Acceptance and Action Questionnaire; ASI-3 = Anxiety Sensitivity Index-3; ASI-R = Anxiety Sensitivity Inventory-Revised; BAI = Beck Anxiety Inventory $\mathrm{BDI}=$ Beck Depression Inventory; BFI = Brief Fatigue Inventory; BFNE = Brief Fear Of Negative Evaluation; CAMS-R = Cognitive Affective Mindfulness ScaleRevised; $C B T=$ Cognitive Behavioral Therapy; CES-D = Centre for Epidemiological Studies-Depression Scale; DASS-21 = Depression, Anxiety, and Stress Scales-21; DERS = Difficulties in Emotion Regulation Scale; ERQ = Emotion Regulation Questionnaire; FFMQ = Five Facet Mindfulness Questionnaire; GAD-7 = 7-item Generalized Anxiety Disorder; HADS = Hospital Anxiety and Depression Scale; HAM-A = Hamilton Anxiety Rating Scale; HRST = Hamilton Rating Scale for Depression; HAM-D = Hamilton Depression Rating Scale; IDAS = Inventory For Depression And Anxiety Symptoms; ISI = Insomnia Severity Index; MAAS $=$ Mindful Attention Awareness Scale; MADRS-S = Montgomery-Asberg Depression Rating Scale; MASQ-AA = Anxious Arousal Subscale; MASQ-AD = Anhedonic Depression; NI = No Intervention, NR = Not Reported; PANAS = Positive Affect Negative Affect Schedule; PDSS = Panic Disorder Severity Scale; PHQ-9 = Patient Health Questionnaire-9; PSS-4 = 4-item Perceived Stress Scale; PSWQ = Penn State Worry Questionnaire; Q-LES-SQ = Quality of Life Enjoyment and Satisfaction Questionnaire; QoL = Quality of Life; QOLI = Quality of Life Inventory; RRS = Rumination with the Ruminative Response Scale; SCS = SelfCompassion with the Self-Compassion Scale; SF-12 = 12-item Short-Form Health Survey; SF-36 = 36-item Short-Form Health Survey; STAI-Y1 = Spielberger State-Trait Anxiety Inventory Form Y; TMS = Toronto Mindfulness Scale; TSST = Trier Social Stress Test; WSAS = Work and Social Adjustment Scale. 
The findings of the literature review consistently linked mindfulness to lower rates of depression and anxiety and greater well-being. ${ }^{11}$

Our overall findings indicate that MBSR is an effective treatment modality for reducing stress, anxiety, and depression. ${ }^{5}$ The studies show the efficacy of MBSR for treating anxiety, depression, and worry in older adults and veterans, even reducing patients' suicidal ideation. Study limitations include failure to not provide details from medical records on veterans' characteristics that could have influenced the effect of treatment, for instance, any significant diagnoses or basic anthropomorphic data; this study is therefore worth following up. ${ }^{14,15}$ The studies selected for the review also reported that mindfulness meditation training reduced anxiety symptoms in patients with GAD and improved coping during a laboratory stress paradigm due through greater resilience to stressful psychological questions. ${ }^{13}$

MBCT was another method that used mindfulness and aimed to reduce rates of relapse and recurrence of major depression and treatment-resistant depression causing emotional reactivity in mindfulness meditation training. These studies have substantial implications for depression. Study limitations include small sample size, restricted statistical power, and a waitlist control design including the possibility of expectancy effects and attrition discrepancies. ${ }^{6,18}$

Another use of mindfulness was its incorporation in the two mindfulness-based therapies, MBSR and MBCT. These therapies were included in regular treatment of patients with clinical diagnoses such as anxiety, stress, and depressive and adjustment disorders. Any variability between mindfulness and control groups was irrelevant; therefore, their standard implementation was not less effective than the patients' regular treatment. One limitation of this study was the inclusion of immigrants in the randomized controlled trial, but those who could not speak Swedish fluently were disqualified from participation. Another limitation of the study was its inclusion of patients with depressive and anxiety disorders. ${ }^{9}$

An important point to be noted in our review was the inclusion of articles describing internet-based mindfulness treatment programs for anxiety. The remote delivery of these programs did not appear to decrease the effectiveness of the mindfulness interventions, showing that the lack of contact with clinicians and other patients in an internet setting is acceptable. ${ }^{7}$

One study investigated the indirect effects of pretreatment mindfulness on social anxiety and suggested that individuals who started CBT with higher levels of mindfulness appeared to experience more symptom reduction following treatment due to lower levels of probability bias at midtreatment. In this study on emotional regulation difficulties and psychopathology, rumination was found to be associated with symptoms of anxiety and depression. ${ }^{3}$

Several studies found that the practice of mindfulness was possibly able to clarify the effects of rumination as a self-critical questioning of one's own emotions and circumstances. ${ }^{22,23}$ Mindfulness involves nonjudgment, which may help ruminators distance themselves from this self-critical questioning, thus reducing the effects of depressive and anxiety symptoms. Moreover, mindfulness improves concrete thinking abilities, focusing on internal and external experiences occurring in the present moment and helping to reduce rumination in depressive and anxiety disorders. 3,24

Mindfulness meditation allows thoughts to pass in and out of consciousness without judgment. This practice reduces rumination on negative thoughts and helps patients with anxiety disorders improve their speech and treat themselves more gently and with less self-judgment. Significant increases in self-reports were found using a Self-Statements During Public Speaking Scale (SSPS), with MBSR being associated with a possible improvement in positive self-regard via reduction of anxiety symptoms. Lower positive emotion linked with the Trier Social Stress Tests (TSST) was shown to predict increased depression symptoms over the following year. ${ }^{13}$

Anxiety disorders are centered on excessive worrying about future events and negative thoughts, and the practice of mindfulness helps individuals focus on the present moment, helping to decrease worry, negative thoughts and feelings, and to ameliorate cognitive dysfunction in older adults. ${ }^{14-16,19}$

The practice of mindfulness develops a state of acceptance, emphasizing emotional regulation strategies and increasing QoL and thereby decreasing invasive thoughts, anxiety, and depression. ${ }^{12}$ Awareness may be one benefit achieved by using stress-reduction techniques in the treatment of mood and anxiety disorders. ${ }^{5}$

The limitations of studies with multifarious constructs may not be entirely mitigated by self-report instruments. The abilities of participants with decreased emotional awareness might affect the accuracy of these measures, and their responses may not reflect the authentic difficulty of participants to perceive their own emotional regulation difficulties and mindfulness skills. ${ }^{21}$

The study published by Kraemer had limitations that should be considered: the trial was fairly small and homogeneous in terms of gender and age. The study relied solely on self-report measures, and their data were cross-sectional in nature. Longitudinal studies are needed to determine how mindfulness skills impact 
panic symptoms among individuals with asthma over time. The sample included young adults who had rather well-controlled asthma. Despite these limitations, the outcomes show that assessing the role of mindfulness, particularly the skill of acting with awareness, on panic symptoms among individuals with asthma is an area for consideration in future research. ${ }^{10}$

In conclusion, the present study suggests that mindfulness can be combined with other therapies to relieve anxiety and mood disorders. Furthermore, mindfulness can be considered effective in therapy protocols with different structures including virtual modalities. Use of mindfulness in scientific models continues to expand.

\section{Disclosure}

No conflicts of interest declared concerning the publication of this article.

\section{References}

1. Baer RA, Smith GT, Hopkins J, Krietemeyer J, Toney L. Using selfreport assessment methods to explore facets of mindfulness. Assessment. 2006;13:27-45.

2. Brown KW, Ryan RM. The benefits of being present: mindfulness and its role in psychological well-being. J Pers Soc Psychol. 2003;84:822-48.

3. Desrosiers A, Vine V, Klemanski DH, Nolen-Hoeksema S. Mindfulness and emotion regulation in depression and anxiety: common and distinct mechanisms of action. Depress Anxiety. 2013;30:654-61.

4. Zhang J, Xu R, Wang B, Wang J. Effects of mindfulness-based therapy for patients with breast cancer: a systematic review and meta-analysis. Complement Ther Med. 2016;26:1-10.

5. Smith B, Metzker K, Waite R, Gerrity P. Short-form mindfulnessbased stress reduction reduces anxiety and improves healthrelated quality of life in an inner-city population. Holist Nurs Pract. 2015;29:70-7.

6. Wong SY, Mak WW, Cheung EY, Ling CY, Lui WW, Tang WK, et al. A randomized, controlled clinical trial: the effect of mindfulnessbased cognitive therapy on generalized anxiety disorder among Chinese community patients: protocol for a randomized trial. BMC Psychiatry. 2011;11:187.

7. Boettcher J, Astrom V, Pahlsson D, Schenstrom $O$, Andersson G, Carlbring P. Internet-based mindfulness treatment for anxiety disorders: a randomized controlled trial. Behav Ther. 2014;45:241-53.

8. Burton M, Schmertz SK, Price M, Masuda A, Anderson PL. The relation between mindfulness and fear of negative evaluation over the course of cognitive behavioral therapy for social anxiety disorder. J Clin Psychol. 2013;69:222-8.

9. Sundquist J, Lilja A, Palmer K, Memon AA, Wang X, Johansson $L M$, et al. Mindfulness group therapy in primary care patients with depression, anxiety and stress and adjustment disorders: randomised controlled trial. Br J Psychiatry. 2015;206:128-35.

10. Kraemer KM, McLeish AC, Johnson AL. Associations between mindfulness and panic symptoms among young adults with asthma. Psychol Health Med. 2015;20:322-31.

11. Lang AJ. What mindfulness brings to psychotherapy for anxiety and depression. Depress Anxiety. 2013;30:409-12.

12. Eyles C, Leydon GM, Hoffman CJ, Copson ER, Prescott $P$, Chorozoglou $M$, et al. Mindfulness for the self-management of fatigue, anxiety, and depression in women with metastatic breast cancer: a mixed methods feasibility study. Integr Cancer Ther. 2015;14:42-56.

13. Hoge EA, Bui E, Marques L, Metcalf CA, Morris LK, Robinaugh $D J$, et al. Randomized controlled trial of mindfulness meditation for generalized anxiety disorder: effects on anxiety and stress reactivity. J Clin Psychiatry. 2013;74:786-92.

14. Lenze EJ, Hickman S, Hershey T, Wendleton L, Ly K, Dixon D, et al. Mindfulness-based stress reduction for older adults with worry symptoms and co-occurring cognitive dysfunction. Int J Geriatr Psychiatry. 2014;29:991-1000.

15. Serpa JG, Taylor SL, Tillisch K. Mindfulness-based stress reduction (MBSR) reduces anxiety, depression, and suicidal ideation in veterans. Med Care. 2014;52:S19-24.

16. Arch JJ, Ayers CR, Baker A, Almklov E, Dean DJ, Craske MG. Randomized clinical trial of adapted mindfulness-based stress reduction versus group cognitive behavioral therapy for heterogeneous anxiety disorders. Behav Res Ther. 2013;51:18596.

17. Wong SY, Yip BH, Mak WW, Mercer S, Cheung EY, Ling CY, et al. Mindfulness-based cognitive therapy $v$. group psychoeducation for people with generalised anxiety disorder: randomised controlled trial. Br J Psychiatry. 2016;209:68-75.

18. Britton WB, Shahar B, Szepsenwol O, Jacobs WJ. Mindfulnessbased cognitive therapy improves emotional reactivity to social stress: results from a randomized controlled trial. Behav Ther 2012;43:365-80.

19. Kim B, Cho SJ, Lee KS, Lee JY, Choe AY, Lee JE, et al. Factors associated with treatment outcomes in mindfulness-based cognitive therapy for panic disorder. Yonsei Med J. 2013;54:145462.

20. Eisendrath SJ, Gillung EP, Delucchi KL, Chartier M, Mathalon $\mathrm{DH}$, Sullivan JC, et al. Mindfulness-based cognitive therapy (MBCT) versus the health-enhancement program (HEP) for adults with treatment-resistant depression: a randomized control trial study protocol. BMC Complement Altern Med. 2014;14:95

21. Roemer L, Lee JK, Salters-Pedneault K, Erisman SM, Orsillo SM, Mennin DS. Mindfulness and emotion regulation difficulties in generalized anxiety disorder: preliminary evidence for independent and overlapping contributions. Behav Ther. 2009;40:142-54.

22. Nolen-Hoeksema S. Responses to depression and their effects on the duration of depressive episodes. J Abnorm Psychol. 1991; 100:569-82.

23. Nolen-Hoeksema S, Wisco BE, Lyubomirsky S. Rethinking rumination. Perspect Psychol Sci. 2008;3:400-24.

24. Watkins ER. Depressive rumination: investigating mechanisms to improve cognitive behavioural treatments. Cogn Behav Ther. 2009;38:8-14.

\section{Correspondence:}

Michele F. Rodrigues

Laboratório de Pânico e Respiração, Instituto de Psiquiatria, Universidade Federal do Rio de Janeiro

Av. Venceslau Bras, 71, fundos

21941-901 - Rio de Janeiro, RJ - Brazil

Tel. : +55 (21) $3938.5506 /$ + 55 (21) 3938.5507

E-mail: michelefrodrigues@gmail.com 